http://dx.doi.org/10.30681/23588403v12i01171180

\title{
LITERATURA INFANTIL BRASILEIRA: COTEJO ENTRE FASE INICIAL E FASE CONTEMPORÂNEA
}

Data de recebimento: $30 / 10 / 2017$

Aceite: 20/12/2017

\author{
Rosana Aparecida LEITÃo DA SILVA (UNIOESTE) ${ }^{1}$
}

\begin{abstract}
Resumo: O presente artigo tem por objetivo realizar um estudo comparativo e evidenciar como a literatura infantil brasileira se transformou desde o seu início até os dias atuais. Propomos uma comparação entre dois contos infantis da literatura brasileira: um de sua fase inicial - Perna de Pau, de Coelho Neto - e outro, - Minha Mentirinha, de Pedro Bandeira - que se insere em sua fase contemporânea. Realizamos o estudo comparativo sob a luz da teoria de autores como: Coelho (1991; 2000), Becker (2008), Turchi (2008) e Gregorin Filho (2009), dentre outros. Nosso trabalho se estrutura com uma breve introdução, segue a análise dos dois contos, logo depois fazemos o cotejo entre os contos e explanado suas características distintas. Na conclusão, observamos que as produções destinadas às crianças se modularam de acordo com o desenvolvimento da sociedade, da concepção de criança, da compreensão da função do texto literário. E, hodiernamente, a literatura infantil procura incentivar a ludicidade, a criatividade e a fruição, tornando-se assim, uma literatura emancipadora.
\end{abstract}

Palavras-chave: Literatura infantil brasileira. Análise comparativa. Fase inicial. Fase contemporânea.

\begin{abstract}
The purpose of this article is to conduct a comparative study and to show how Brazilian children 's literature has transformed from the beginning to the present day.We propose a comparison between two children's stories in Brazilian literature: one of its initial stages - Perna de Pau, by Coelho Neto - and another Minha Mentirinha by Pedro Bandeira - which is inserted in its contemporary phase.We performed the comparative study under the light of authors' theory as: Coelho (1991; 2000), Becker (2008), Turchi (2008) and GregorinFilho (2009), among others.Our work is structured with a brief introduction, follows the analysis of the two tales, after we make the comparison between the stories and explained its different characteristics.In conclusion, we see that the productions aimed at children are modulated according to the development of society, the conception of children, and the understanding of the function of the literary text.And, nowadays, children's literature seeks to encourage playfulness, creativity and enjoyment, thus becoming an emancipatory literature.
\end{abstract}

Keywords: Brazilian children's literature. Comparative analysis. Initial phase. Contemporary phase.

\section{Introdução}

A história da literatura infantil brasileira, ao considerarmos apenas o viés literário com aporte no texto escrito e impresso, tem sua gênese no final do século XIX, por volta de 1880. Neste momento, se iniciam as produções literárias voltadas para as crianças em nosso

\footnotetext{
${ }^{1}$ Licenciada em Letras (UNIOESTE - FI). Aluna do Programa de Pós-Graduação Stricto Sensu em Letras, Nível de Mestrado Profissional em Letras - PROFLETRAS. Universidade Estadual do Oeste do Paraná (UNIOESTE) - Cascavel - PR - Brasil. Professora da Secretaria Municipal de Foz do Iguaçu - PR. E-mail: sourosana@hotmail.com
} 


\section{Revista de Estudos Acadêmicos de Letras}

país. As obras daquele instante histórico, que se insculpem entre 1880 e 1920, são marcadas pelo caráter didático-moralizador. Hodiernamente, a literatura infantil se mostra com outras características bem distintas daquelas iniciais.

Nos últimos trinta anos, a produção literária destinada ao público infantil ganhou outros contornos, houve um abrandamento ou abandono do caráter didático-pedagógico dando lugar a uma literatura que primazia a leitura crítica, a inferência. O leitor tem a possibilidade de produzir os sentidos do texto com o autor. O texto não está pronto de antemão, o texto literário infantil da atualidade imprescinde que haja a participação do leitor.

Silva e Niaderauer (2014, p. 3), sobre a compreensão da função da literatura nesses dois momentos ressaltam que na primeira fase de nossa literatura infantil "queria-se o livro como instrumental para o controle do desenvolvimento intelectual da criança (...) e como meio para manipular suas emoções", contudo, com o desenvolvimento da concepção sobre infância e criança, na época atual, "passa a pensar-se a importância do lúdico, da imaginação, emoção, o que leva à consideração do prazer da leitura, e do livro infantil como arte literária, não didática".

Diante desses pressupostos, temos por objetivo neste trabalho realizar um estudo comparativo em literatura infantil e para tanto, a fim de realizar o cotejo, estabelecemos como parâmetros comparativos dois períodos da literatura infantil brasileira: literatura infantil de 1880 a 1920 e a literatura infantil contemporânea, situada temporalmente a partir da década de 1990 aos dias atuais.

Evidenciaremos no trabalho a análise comparativa entre dois contos produzidos nos períodos em comento, dando ênfase às características da literatura infantil em cada um desses momentos históricos, e para tanto nos valeremos dos textos Perna de Pau, de Coelho Neto (1864-1934), e Minha Mentirinha, de Pedro Bandeira (1942).

Quanto à estrutura de nosso texto, faremos inicialmente a análise do conto de Coelho Neto, que está inserido na primeira fase da literatura brasileira e, logo em seguida, discutiremos a obra de Pedro Bandeira, autor contemporâneo, conto produzido na primeira década do nosso século. No passo seguinte, expomos sucintamente as diferenças notadas e, terminamos com uma breve consideração final a despeito do tema tratado.

\section{Conto da fase inicial da Literatura Infantil no Brasil}




\section{Revista de Estudos Acadêmicos de Letras}

A história da literatura infantil brasileira, sob a perspectiva de textos escritos, tem uma primeira fase compreendida entre o final do século XIX e início do século XX, precisamente entre 1880 e 1920. De acordo com Coelho (1991), a literatura infantil brasileira, em similitude com a literatura infantil de Portugal, tem em sua gênese o caráter didatizante, educativo ou moralizador. Nesse sentido, Coelho (1991, p. 104) observa que quase como regra geral "as manifestações literárias desses séculos formadores da literatura ocidental surgem impulsionadas por uma intenção didática, moralizante ou educadora".

A preocupação política nesse momento era com a modernização do país e uma consciência moralizadora e a escola era uma das responsáveis por alcançar esses objetivos além de incentivar valores patrióticos, principalmente nas crianças. A fim de ter consolidado tais propósitos a educação escolar se valia da literatura infantil.

Seguindo esse entendimento, a literatura destinada à criança em sua fase inicial "tinha função formadora, ao apresentar modelos de comportamento com a finalidade de reforçar valores sociais vigentes" (LUFT; RÖSING, 2007, p. 67). Diante deste contexto, o autor Coelho Neto no seu texto narra uma pequena história em que as ações das personagens infantis se transfiguram no decorrer do conto, as atitudes de desrespeito e pilhéria são substituídas por ações de acolhimento e atenção ao personagem idoso.

Becker (2008, p. 36), analisa que, "permeável às solicitações da sociedade, a literatura infantil integrou-se aos esforços de instalação da cultura nacional, vinculada à escola e à valorização do nacionalismo".

No conto Perna de Pau, de Coelho Neto, verificamos esses indícios. Há de uma maneira sutil a valorização do desprendimento do indivíduo em função da pátria, pondo em risco sua vida em função dos seus compatriotas. Observemos essa característica no seguinte excerto do conto: "Muitos dos meus companheiros lá ficaram, devorados pelo dragão terrível; eu, mais feliz, apenas perdi uma perna: e não me arrependo, nem lastimo a dor que sofri...” Netto (1931).

Marcadamente, tem-se aquilo que Gregorin Filho (2009) categorizou como literatura de cunho humanista dramático.

A literatura infantil foi usada como meio de moralizar as crianças. No conto em estudo, as crianças no início apresentaram uma atitude indesejada quando insultaram o senhor que usava muleta: "quando o inválido passava, rompiam em assuada: - Oh, perneta!". No entanto, após ouvirem a história do senhor, passaram a respeitá-lo e valorizá-lo. O texto leva a criança a converter uma ação inadequada em uma atitude digna. 
[...] quando voltei com o peito coberto de medalhas, ainda achei minha velha mãe que me abençoou. Hoje estou velho e doente, e os meninos riem-se de $\operatorname{mim} . .$.

- Não riremos mais! - disse um pequeno com os olhos rasos dágua; e atirando-se ao pescoço do velho soldado, pôs-se a dizer, comovido:

- Não riremos mais! Não riremos mais! (NETTO, 1931).

Percebe-se a intenção de combate à impiedade e enaltecimento do auxílio, da gentileza e respeito aos mais velhos: "e o Perna de Pau, no meio das crianças que procuravam abraçá-lo, rindo, mas com duas lágrimas nos olhos...", “e todos festejavam o inválido, prometiam-lhe presentes, abraçavam-no" (NETTO, 1931).

Segundo Turchi (2008, p. 2), no início da literatura infantil brasileira o gênero sofria de precariedade em virtude da "construção literária condicionada a um horizonte de dominação entre autor-texto-leitor".

Outra característica do texto literário destinado à criança daquele momento histórico foi, como admoesta Gregorin Filho (2009), o respeito incondicional pelas instituições que governam a vida do indivíduo, que são a família, a escola, a pátria. No excerto seguinte do conto de Coelho Neto, essa característica se evidencia: "Um dia o diretor chamou-o (...), quando os meninos saíram para o pátio, viram com surpresa o Perna de Pau sentado tranquilamente em um dos bancos. Receosos murmuraram: - Vem dar parte! Vem queixar-se ao diretor!" (NETTO, 1931).

A linguagem usada no conto é polida e rebuscada. Naquele período da literatura infantil brasileira, o uso de linguagem padrão e formal era a que predominava nos contos infantis: viam-no; conheciam-no; longe de agastar-se; venha até cá.

Os intelectuais daquele momento histórico, os escritores da insipiente literatura infantil brasileira, pretendiam a modernização de nosso país e para tanto percebiam na escola um meio ao alcance de tal propósito. Desta feita, a literatura infantil escolar estava imbuída de preceitos moralizantes, pedagogizantes e patrióticos.

A literatura infantil daquele momento, portanto, tinha como pretensão criar nos leitores infantes a valorização e o amor soberano ao país, admoestando o sentimento de orgulho por se doar à pátria, pondo a sua própria vida em função da nação, não importando se nesse intento poderia perdê-la, ou ficar mutilado, tais consequências eram motivo de orgulho e prazer por defender o Brasil.

As personagens eram caracterizadas com sentimento grandioso pela pátria, com noção de amor à família e ao próximo. Atitudes e ações indesejadas eram demonstradas e no 
desenvolvimento da narrativa tais comportamentos eram modificados, dando lugar à bondade, afeição. Os textos tinham o objetivo de converter e mudar atitudes desabonadoras em boas ações e sentimentos.

A literatura infantil esteve assim caracterizada até que surge o marco divisor de nossa história literária infantil: Monteiro Lobato, na década de 1920. Nesse sentido, são oportunas as palavras de Gregorin Filho (2006), que sintetiza:

A educação e a leitura no Brasil, até o surgimento de Monteiro Lobato, eram o reflexo dos paradigmas vigentes, ou seja, o nacionalismo, o intelectualismo, o tradicionalismo cultural com modelos de cultura a serem imitados - desprezando-se totalmente as manifestações culturais surgidas aqui no país -; divulgavam-se o humanismo dramático e o moralismo religioso, com as exigências de retidão de caráter, de honestidade, de solidariedade e de pureza de corpo e de alma em conformidade com os preceitos cristãos. (GREGORIN FILHO, 2006, p. 190).

A partir da década de 1970, de acordo com Turchi (2008), a literatura infantil brasileira institui um período de numerosa produção literária. Desde então, o gênero passou a abordar o momento histórico social brasileiro. Surgem nomes representativos do gênero como Ruth Rocha, Ana Maria Machado, Lygia Bojunga Nunes, Ziraldo dentre outros que ainda continuam a publicar atualmente.

\section{Conto na Literatura Infantil brasileira contemporânea}

Nesse ponto do estudo almejamos vislumbrar em um texto escrito na primeira década do século presente, um conto da literatura infantil - Minha Mentirinha - escrito por Pedro Bandeira, características que constituem a literatura escrita para crianças. A atividade a que nos propomos não é simples, e isso se revela pelo fato de estarmos inseridos no período que pretendemos analisar e os elementos que constituem a presente fase ainda estão sendo delineados.

O aporte teórico sob o qual nos embasamos é integrado por artigos de estudiosos que procuram detectar as ocorrências de técnicas, estilos, temas e usos da linguagem recorrentes nas atuais produções destinadas aos leitores em formação e que, então, formam o rol de itens que possibilitam determinar uma fase histórica da literatura infantil. Para o estudo citamos os textos de Luft; Rösing (2007), Turchi (2008), Kirchof; Bonin; Silveira (2013), dentre outros. 


\section{Revista de Estudos Acadêmicos de Letras}

Podemos inferir, a partir daqueles estudiosos, que a literatura infantil brasileira chega ao final do século XX, década de 90 e início desse século até os dias presentes com outras características que vieram se desenvolvendo durante o lapso temporal ocorrido entre 1920 e 1990. Vejamos na sequência alguns desses elementos caracterizadores da atual literatura infantil brasileira.

Kirchof; Bonin; Silveira (2013) apontam como uma característica da literatura infantil contemporânea a abordagem de temas ligados à concepção das diferenças étnicas, etárias, raciais, de deficiência, de orientação sexual, de gênero, de confrontação corporal.

No texto de Bandeira (2006), ocorre o embate geracional, a abordagem do assunto referente às diferenças etárias é de certa maneira implícita em todo o texto quando o avô da personagem principal a todo o momento usa a expressão “no meu tempo". De outra feita, há a menção ao tema de forma explícita ao final do texto quando o menino incorpora o dizer do avô em conversa com a avó e esta, replica dizendo: "Ora, querido. Eu estou muito viva. Meu tempo é agora!" (BANDEIRA, 2006).

De acordo com Luft; Rösing (2007, p. 76), “a literatura infantil contemporânea oferece uma nova concepção de texto escrito, aberto a múltiplas leituras, questionamentos e reflexões, transformando a literatura para crianças em suporte para experimentação do mundo".

Nesse sentido, percebemos no texto em comento a efetivação dessa característica uma vez que o autor procura promover a reflexão do leitor sobre um acontecimento ordinário passível de acontecer com qualquer criança. O pequeno leitor poderá com a leitura do conto experimentar outra vivência, construindo, assim, suporte cognitivo para possíveis enfrentamentos que possa vir a ter em seu cotidiano.

Há neste conto de Bandeira conflitos inerentes à realidade infantil: perder a noção de tempo por estar em uma atividade divertida, a maneira como se safar de uma repreensão por uma falta cometida, como lidar com a autoridade dos familiares responsáveis, essas são situações conflituosas vivenciadas pelas crianças e ao vê-las representadas no texto o leitor é capaz de perceber possíveis soluções as suas inquietações.

A presença de informações da contemporaneidade na caracterização do tempo, do espaço e dos conflitos e a apresentação de temas voltados para as relações interpessoais são elementos caracterizadores da literatura atual de acordo com Turchi (2008).

O texto Minha Mentirinha dispõe desses elementos visto que o conflito acontece em uma família na qual os avós vivem na mesma residência, são eles responsáveis pelos cuidados 


\section{Revista de Estudos Acadêmicos de Letras}

com a criança enquanto os pais estão fora, a avó cuida dos afazeres da casa que tem vários utensílios atuais: “(...) sentei à mesa para o almoço que a vovó tinha requentado no microondas" (BANDEIRA, 2006), além das atividades domésticas a avó também usa dispositivos tecnológicos atuais, o computador e a rede mundial de informação: "Fui atrás da vovó, que tinha deixado a louça na máquina de lavar pratos e sentava-se ao computador, conectando-se à Internet” (BANDEIRA, 2006).

O relacionamento interpessoal é percebido na relação de camaradagem entre o avô e o neto, em toda extensão do texto; e ainda, no início do conto, no relacionamento das crianças com o funcionário responsável na escola: “O bedel, que entendia dessas necessidades, sempre deixava a gente se divertir um pouco antes de aparecer fingindo cara de bravo e mandando a gente pra casa" (BANDEIRA, 2006).

Turchi (2008) delimita como outra característica literária infantil a "ponte de diálogo entre a voz do adulto e a voz da criança", a maleabilidade da condição de normatividade, preconizando o diálogo e a compreensão mútuos. No texto, o avô não repreende efetivamente o neto, contudo faz com que ele perceba que não foi enganado. E para fazer isso, surge mais uma característica do momento atual dos textos para crianças que, de acordo com a autora (2008) é o uso de lembranças do passado, especialmente memórias nostálgicas dos adultos sobre a infância. Em Minha Mentirinha (2006), o avô recorda e relata situação parecida vivida por ele no passado, em sua meninice, e que se assemelha com as que o neto está vivenciando.

Tem prevalecido quanto à linguagem o uso mais aberto e coloquial, conforme Gregorin Filho (2009, p. 32), é uma "linguagem literária que busca a invenção e o aspecto lúdico da linguagem, ou seja, uma literatura que mostra um mundo em construção para uma criança que passa a ser vista como um ser em formação."

Observamos no presente estudo apenas alguns dos muitos elementos que caracterizam a literatura infantil brasileira contemporânea, isto porque este estudo tem por objetivo a comparação entre dois textos do gênero discursivo conto de duas fases distintas da literatura infantil.

\section{Cotejo entre fases: inicial e contemporânea}

A observação que fizemos, tendo como objetos de análise dois textos escritos em épocas diferentes, com fulcro nos estudos de pesquisadores da literatura infantil brasileira, nos possibilitou produzir a tabela comparativa que a seguir apresentamos. 


\section{Revista de Estudos Acadêmicos de Letras}

Os autores são representativos na literatura infantil brasileira em suas épocas.

\begin{tabular}{|c|c|c|}
\hline $\begin{array}{c}\text { PARÂMETROS } \\
\text { COMPARATIVOS }\end{array}$ & $\begin{array}{l}\text { Fase Inicial } \\
1880-1920 \\
\end{array}$ & $\begin{array}{c}\text { Fase Contemporânea } \\
1990 \text { - nossos dias }\end{array}$ \\
\hline Autor & $\begin{array}{l}\text { - Coelho Neto. } \\
(1864-1934)\end{array}$ & $\begin{array}{l}\text { - Pedro Bandeira. } \\
\text { (1942) }\end{array}$ \\
\hline Conto & - Perna de pau. & - Minha mentirinha. \\
\hline $\begin{array}{c}\text { Perspectiva Social e } \\
\text { Política }\end{array}$ & $\begin{array}{l}\text { - Modernização do país; } \\
\text { - Valorização da pátria; } \\
\text { - Período de conflitos } \\
\text { políticos. }\end{array}$ & $\begin{array}{l}\text { - Respeito à diversidade cultural e } \\
\text { social; }\end{array}$ \\
\hline Concepção de Criança & $\begin{array}{l}\text { - Adulto em miniatura; } \\
\text { - Educado para servir aos } \\
\text { Interesses do país. }\end{array}$ & $\begin{array}{l}\text { - Ser dotado de personalidade que } \\
\text { se encontra em fase de } \\
\text { desenvolvimento e formação. }\end{array}$ \\
\hline Linguagem & $\begin{array}{l}\text { - Cuidado exacerbado com a } \\
\text { linguagem; } \\
\text { - Uso da norma padrão. }\end{array}$ & - Linguagem coloquial. \\
\hline Relação com Adulto & $\begin{array}{l}\text { - Relacionamento } \\
\text { hierárquico; } \\
\text { - Obediência irrestrita à } \\
\text { autoridade constituída. }\end{array}$ & $\begin{array}{l}\text { - Relacionamento de } \\
\text { camaradagem; } \\
\text { - O adulto (autor) se adéqua à } \\
\text { criança. }\end{array}$ \\
\hline Função do texto Literário & $\begin{array}{l}\text { - Função moralizadora, } \\
\text { educadora; } \\
\text { - Difundir os valores da } \\
\text { sociedade; } \\
\text { - Caráter didatizante. }\end{array}$ & $\begin{array}{l}\text { - Literatura emancipadora; } \\
\text { - Incentivar a ludicidade, a } \\
\text { criatividade, a fruição. } \\
\text { - Abrandamento ou supressão do } \\
\text { caráter didatizante. }\end{array}$ \\
\hline
\end{tabular}




\section{Revista de Estudos Acadêmicos de Letras}

Tabela - Fonte: Dados da análise e pesquisa bibliográfica.

Os textos escolhidos para análise foram do gênero discursivo conto, por se tratarem de textos curtos, que retratam uma situação ocorrida em um curto lapso de tempo.

Diante da tabela, podemos constatar que houve, nos quase cem anos que separam as duas produções, inúmeras mudanças e essas transformações se refletem na escrita do texto direcionado à criança.

\section{Conclusão}

Coelho (2000, p. 141) ao confrontar os paradigmas tradicionais versus os emergentes preleciona sobre a visão de criança nos tempos atuais em que "a criança é vista como um ser em formação, cujo potencial deve desenvolver-se em liberdade, mas orientado no sentido de alcançar a maior plenitude em sua realização" e assim a literatura direcionada aos infantes sofre as modificações que a sociedade pleiteia.

Ao finalizarmos esse estudo de análise, percebemos que ainda há muito por se pesquisar a despeito do tema. As mudanças que aconteceram ao enfoque dado à literatura infantil brasileira muito têm a ver com a compreensão da criança como um ser em processo de desenvolvimento e formação.

Logo, a literatura infantil brasileira, em seus primórdios, é muito distinta do que se percebe nos dias atuais. O tempo passou, as concepções de criança, infância e literatura infantil, de igual modo, se desenvolveram e modificaram. O que deu origem à nova configuração da literatura infantil que ora se delineia.

\section{Referências}

BANDEIRA, Pedro. Minha mentirinha. In: Biblioteca Pedro Bandeira. Disponível em < http://www.bibliotecapedrobandeira.com.br/pdf/minha_mentirinha.pdf $>$ Acesso em 28 mai. 2017.

BECKER, Celia Doris. História da literatura infantil brasileira. In: SARAIVA, Juracy Assmann (org.). Literatura e Alfabetização[recurso eletrônico], do plano do choro ao plano da ação. Porto Alegre: Artmed, 2008. P. 35-41.

COELHO, Nelly Novaes. Panorama histórico da literatura infantil/juvenil - das origens Indo-Europeias ao Brasil contemporâneo. 4 ed. rev. São Paulo: Ática, 1991. 
A literatura infantil: um objeto novo. In:

vida. São Paulo: Peirópolis, 2000. p. 127-141.

Literatura: arte, conhecimento e

GREGORIN FILHO, José Nicolau. Literatura infantil: múltiplas linguagens na formação de leitores. São Paulo: Melhoramentos, 2009.

Literatura infantil brasileira: da colonização à busca da identidade. In Via Atlântica, n. 9, jun. 2006. p. $\quad$ 187-194 $\quad$ Disponível $\quad$ em <http://www.revistas.usp.br/viaatlantica/article/view/50049/54177> Acesso em 13 mar. 2017.

KIRCHOF, Edgar Roberto; BONIN, Iara Tatiana; SILVEIRA, Rosa Maria Hessel. Literatura infantil e diferenças. In: Educação e realidade. v. 38, n. 4, p. 1045-1052. Porto Alegre: out./dez. 2013.

LUFT, Gabriela; RÖSING, Tania M. K. A nova leitura literária infantil e juvenil no contexto dos centros culturais multimidiais. In: Revista Língua e Literatura. V. 10, n. 14, p. 67-83. Frederico Westphalen, Jul 2007.

NETTO, Coelho. Perna de Pau. In: BILAC, Olavo; NETTO, Coelho. Contos Pátrios. Francisco Alves, RJ, 1931, 27 $7^{\text {a }}$ ed. Disponível em: < http://www.unicamp.br/iel/memoria/Ensaios/LiteraturaInfantil/17contos.htm> Acesso em 28 mai. 2017.

SILVA, Denise Almeida; NIEDERAUER, Silvia Helena. Leitura: a literatura infantil e juvenil hoje. In Revista literatura em debate, v. 8, n. 14, p. 1-7, ago. 2014. Disponível em: $<$ http://revistas.fw.uri.br/index.php/literaturaemdebate/article/viewFile/1633/1809> Acesso em 28 mai. 2017.

TURCHI, Maria Zaira. Tendências atuais da literatura infantil brasileira. In: XI Congresso Internacional da ABRALIC: tessituras, interações, convergências. São Paulo: USP. 13-17 jul. 2008. Disponível em:

http://www.abralic.org.br/eventos/cong2008/AnaisOnline/simposios/pdf/047/MARIA_TURC HI.pdf> Acesso em: 28 mai. 2017. 